\title{
BASAL WATER AND HIGH-PRESSURE BASAL ICE
}

\author{
By J. WEERTMAN
}

(Department of Materials Science and Engineering, Materials Research Center, and Department of Geological Sciences, Northwestern University, Evanston, Illinois 60201, U.S.A.)

Abstract. Expressions are found for the water pressure in channels and cavities under a temperate glacier in a steady state. By steady state is meant that not only is the sliding velocity constant but also the basal water flow as well as the basal water production. The calculations are based on a simplified bimodal obstacle bed. One-size obstacles are of the magnitude of the conventional "controlling" obstacles size. The other obstacle size is several orders of magnitude larger than the controlling size. The large obstacles are introduced in order to investigate the storage of large amounts of water at the bed. The effect of the missing obstacles is mimicked by adding a friction stress whose values decrease linearly with ice-rock separation. It is found that water flow is primarily in a water film if the water flux is below a critical limit. The physical reason for this result is that a minimum water flow must be exceeded in order to keep a water channel open in high ice-pressure regions in front of obstacles. The new ingredient in our analysis of water flow is the explicit account taken of the effect of excess ice pressure (at the up-stream side of obstacles) on the closing of water channels. The excess ice-pressure regions play a critical role in the development of water films. The recognition of the possible importance of high-pressure basal ice regions to the regulation of water flow is the primary result of this paper. It is found that, in steady state, the water pressure is close to the overburden ice pressure provided that water transported through Nye channels is only a minor part of the total. The water flows primarily in a water film. If a large flux of upper-surface melt water descends to the bed, this water could cause a reduction of the water pressure and a channelization of the water flow.

RÉsumÉ. Eau basale et forte pression dans la glace de fond. Des expressions sont obtenues pour la pression de l'eau dans les chenaux et cavités sous un glacier tempéré en état de régime. Par état de régime on entend que non seulement la vitesse de glissement est constante mais aussi que l'écoulement de l'eau à la base ainsi que la production d'eau au fond sont fixes. Les calculs sont basés sur un obstacle du lit bimodal simplifié. Certains de ces obstacles sont de taille comparable à celle de l'obstacle-contrôle conventionel. Tandis que les autres sont d'une taille plusieurs fois supérieure. Les obstacles de grande taille sont introduits de façon à voir l'effet de stockage d'importantes quantités d'eau sur le lit. L'effet des obstacles ennoyés est simulé par l'introduction d'une contrainte de frottement dont l'importance décroit linéairement avec la distance au lit. On obtient que l'écoulement de l'eau est principalement causé par le film d'eau tant que le flux reste au-dessous d'une limite critique. La raison physique de ce résultat vient de ce qu'un écoulement d'eau minimum peut être dépassé de façon à conserver ouverts les chenaux d'eau dans les zones de fortes pression de la glace à l'amont des obstacles. Ce nouvel "ingrédient" dans nos analyses de l'écoulement de

\section{INTRODUCTION}

The primary focus of this paper is on the effect of high ice-pressure regions on the closure of small Röthlisberger channels ( $R$-channels) and the water flow l'eau est la prise en compte explicite de l'effet d'excés de pression de la glace (sur la face amont des obstacles) sur la fermeture des chenaux d'eau. Ces régions de pression de glace en excès jouent un rôle critique dans le développement des films d'eau. La mise en évidence de la possible importance des régions de glace basale à forte pression dans la régulation de l'écoulement de l'eau est le résultat principal de cet article. On obtient que pour un état stationnaire, la pression de l'eau est voisine de celle de la glace susjacente, pourvu que l'eau évacuée à travers les chenaux de Nye reste une faible partie de l'écoulement total. L'écoulement d'eau principal se fait dans un film d'eau. Si un fort afflux d'eau de fonte atteint le lit, alors cette eau peut causer une diminution de la pression dans l'eau et créer un écoulement en chenaux.

ZUSAMMENFASSUng. Wasser und Eis unter hohem Druck am Untergrund. Für den Druck von Wasser in Kanälen und Hohlräumen unter einem stationären temperierten Gletscher werden Formeln hergeleitet. Unter "stationär" ist dabei zu verstehen, dass nicht nur die Gleitgeschwindigkeit sondern auch der Wasserfluss sowie der Wassernachschub am Untergrund konstant sind. Die Berechnungen setzen ein vereinfachtes Bett mit zwei verschiedenen Hindernistypen voraus. Die Grössenordnung der ersten Hindernisart entspricht der üblichen Grösse von "Steuerhindernissen"; diejenige der anderen Hindernisse ist einige Ordnungen grösser. Die grossen Hindernisse werden eingeführt, um die Speicherung grosser Wassermengen am Bett untersuchen zu können. Das Fehlen von Hindernissen wird durch die Einführung einer Reibungskraft simuliert, deren Grösse linear mit dem Zwischenraum zwischen Eis und Fels abnimmt. Es ergibt sich, dass das Wasser vor allem dann in einem Film fliesst, wenn der Fluss unter einer kritischen Grenze bleibt. Die physikalische Begründung für dieses Ergebnis besteht darin, dass ein minimaler Wasserfluss überschritten werden muss, wenn Wasserkanäle in Hochdruckgebieten vor Hindernisen offen gehalten werden sollen. Die Neuerung in dieser Analyse des Wasserflusses ist in der expliziten Berücksichtigung des Einflusses übermässigen Eisdruckes (auf der stromaufwärts liegenden Seite der Hindernisse) auf das Schliessen von Wasserkanälen zu sehen. Die Gebiete mit übermässigem Eisdruck spielen in der Entwicklung von Wasserfilmen eine kritische Rolle. Die Erkenntnis der möglichen Bedeutung von Gebieten unter hohem Druck im Eis am Untergrund auf die Regelung des Wasserflusses ist das wesentliche Ergebnis dieser Arbeit. Es zeigt sich, dass bei stationärem Zustand der Wasserdruck nahe beim Druck des überlagernden Eises liegt, sofern das Wasser, das in Nye-Kanälen fliesst, nur einen kleinen Bruchteil des Gesamtflusses ausmacht. Das Wasser fliesst dann vor allem in einem Film. Erreicht ein starker Strom von Oberflächenschmelzwasser das Bett, so könnte dieses Wasser einen Druckabfall und eine Kanalisierung des Wasserflusses bewirken.

through them. Because R-channels exist within the basal ice, they move down-glacier with the flowing ice. Since the ice pressure can change by large amounts along an ice-flow path past bed irregularities, the velocity of R-channel closure must also change by large amounts along the length 
of a channel. This change of closure velocity must affect the water flow through a channel-linked cavity system. Up to now, no account seems to have been taken of the effect on and importance of local high ice-pressure regions on the water flow through a channel cavity system.

The glaciers that are considered in this paper are temperate ones that rest on a rock bed. The bed is rough in both the transverse and the longitudinal directions. It is assumed that relatively little water leaks through the rock formation beneath the bed. Almost all the water flows along the bed.

The recent account of the surge of Variegated Glacier (Alaska) by Kamb and others (1985) raises again the question of just how basal water can change the sliding motion of glaciers. A great deal of theoretical work has been accomplished on the problem of the flow of water at the bed of a glacier and how water affects the sliding motion. (See, for example, the papers of Lliboutry (1968, 1983), Röthlisberger (1972), Shreve (1972), Weertman (1972, 1979), Nye (1973), Iken (1981), Walder (1982, unpublished), Weertman and Birchfield (1983[a], [b]).)

In order to make the physical arguments as clear and simple as possible, the analysis of this paper is based on a bimodal obstacle-size bed. One set of obstacles of the model bed is of a size of the order of the "controlling" obstacles size and "controlling" wavelength (Nye, 1969; Kamb, 1970; Weertman, 1979). The largest increase in local ice pressure exists in front of the obstacles of controlling size. Thus, it makes sense in a bimodal bed model to have one obstacle size equal to the controlling size.

Another set of obstacles, which are several orders of magnitude larger than the obstacles of controlling size, is also part of the model bed. The increase of pressure within the ice ahead of such obstacles is, usually, quite modest. The main purpose of introducing very large obstacles is to enable the bed model to have the capability of storing large amounts of water in cavities behind these obstacles. The bimodal bed thus could give some insight into the conditions for large water storage as well as large uplifts of the upper ice surface. The presence of the large obstacles also prevents runaway sliding when so much water is at the bed that all of the smaller obstacles are drowned. (The reader should appreciate that the larger obstacles play only a secondary role in the theory of this paper.)

We emphasize that, with one exception, the physical ideas in this paper are not new. They can be found in the papers mentioned earlier. In particular, the paper of Walder (unpublished) strongly influenced the material in the present paper. In this paper use is made of a very simplified model glacier bed which is realistic enough, we believe, to bring out the essential physics of the problem.

It is assumed throughout this paper that a glacier lies on a solid rock "hard" bed. It is entirely possible, of course, for a glacier to rest on a "sof $t$ " bed of deformable till. Results presented at the recently held Interlaken workshop

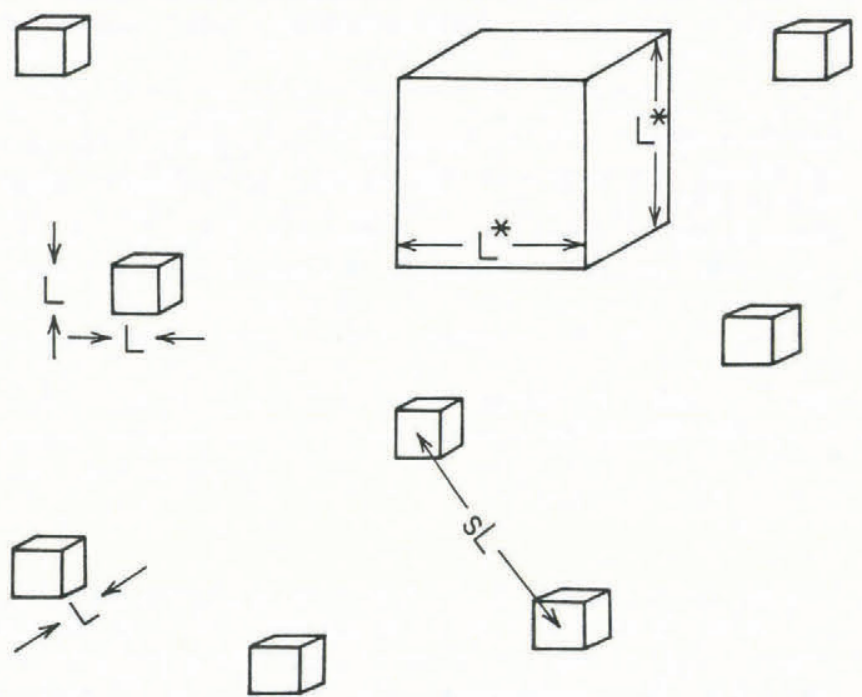

Fig. 1. Bimodal obstacle glacier bed. on hydraulic effects at a glacier bed revealed that "sliding" motion produced by deformation of till beneath glaciers may be very common and may account for the fast velocities of ice streams and surging glaciers. (The percentage of all ice streams and surging glaciers whose fast motion might be controlled by this mechanism is not known.) The theory of this paper, obviously, does not apply to glaciers resting on a soft bed. It is also assumed in this paper that the volume of morainal material within the basal ice is so small that the rheology of basal ice is that of clean ice.

The presence of Nye channels (N-channels) is ignored in the theory of this paper. Therefore, the theory is applicable only for situations in which so much water flows down the glacier bed that $\mathrm{N}$-channels, whose capability of transporting water is limited, carry only a minor part of the total water flux. (N-channels are water channels incised into the bedrock; R-channels are channels cut within the basal ice. The radius of an $\mathrm{N}$-channel is fixed; that of an $\mathrm{R}$-channel is not.)

The glacier bed used is that shown in Figure 1. In this bed are obstacles of size $L$ that are separated by a distance $s L$, where $s$ is large compared with 1 . In addition, the bed contains much larger obstacles of size $L^{*}$ that are separated by a distance of $s^{*} L^{*}$, where $s^{*} \approx s$. The obstacles are shown as cubic-shaped. They can also be considered to have a hemispherical shape.

\section{THEORY}

\section{Obstacles in a cubic array}

The essential result of the theory of this paper is more easily demonstrated with a simplified version of the theory. Assume that only one-size obstacle exists in the model bed of Figure 1. Assume the ice-rock interface between the obstacles can support no shear stress. Assume no water is produced at the bed by geothermal heat and no water reaches the bed from the upper ice surface. Assume the obstacles are of hemispherical shape and are arrayed in the simple cubic pattern shown in Figure 2.

All the mechanical work of sliding occurs around the obstacles. This work is converted into heat that produces melting of ice near the obstacles. The water produced flows in a linked cavity-channel system also shown in Figure 2.

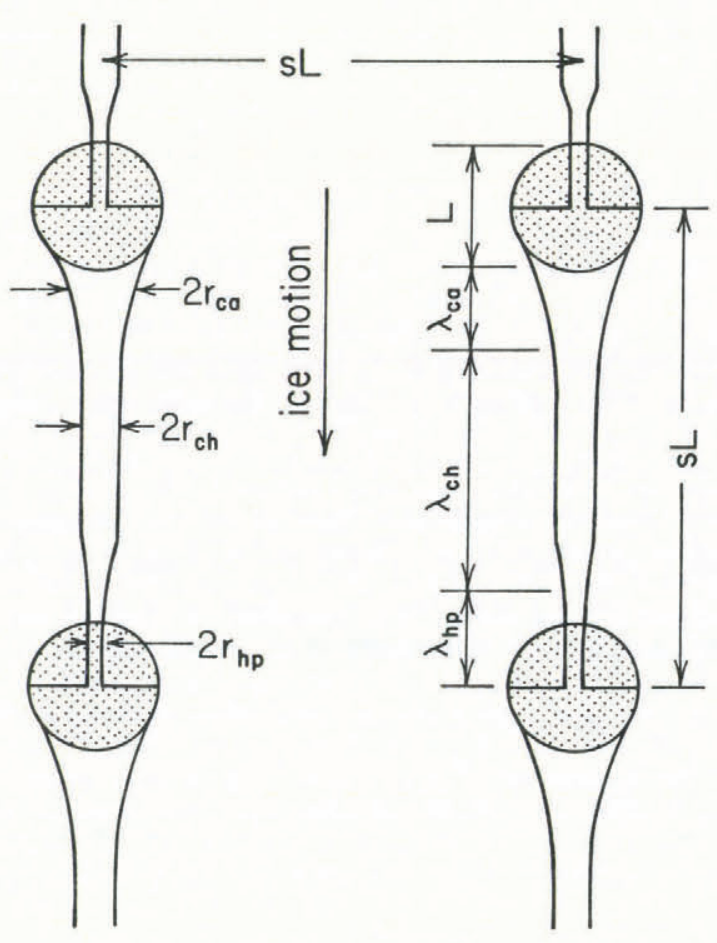

Fig. 2. Looking down on a single obstacle-size glacier bed where the obstacles are arranged in a simple cubic pattern. Water cavities and connecting channels are also shown. 


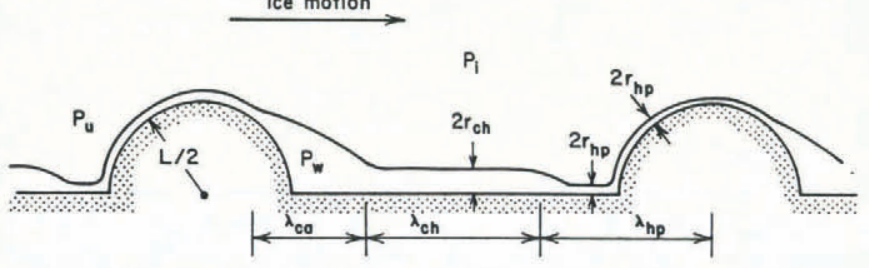

Fig. 3. Cross-section of water-flow path through water cavities and connecting channels of Figure 2.

In Figure 3 is shown a cross-section of a water-flow path. The path consists of a cavity of length $\lambda_{\mathrm{ca}}$, and approximate radius $r_{\mathrm{ca}}=L / 2$, an exit channel of length $\lambda_{\mathrm{ch}}$ and radius $r$, and a constricted channel through high-pressure ice of length $\lambda_{h p}$ and radius $r_{h p}$.

Let $P_{i}$ be the average overburden ice pressure. $\left(P_{\mathrm{i}}=\rho g h\right.$, where $\rho$ is the density of ice, $g$ is the acceleration of gravity, and $h$ is the thickness of the glacier.) Let $P_{\mathrm{u}}$ be the average ice pressure on the up-stream side of an obstacle and $P_{\mathrm{d}}$ be the pressure on the down-stream side. The pressure $P_{\mathrm{u}}$ exists over a distance of the order of $L$ in front of an obstacle and $P_{\mathrm{d}}$ over a similar distance behind the obstacle. If the sliding velocity is $V$, the pressure $P_{\mathrm{u}}$ is given by the equation

$$
V=c_{\mathrm{v}} B L\left(P_{\mathrm{u}}-P_{\mathrm{i}}\right)^{3}
$$

where the dimensionless constant $c_{\mathrm{v}}$ is of order of 0.1 to 1 and $B$ is the constant of Glen's power-law creep equation for ice:

$$
\mathrm{d} \epsilon / \mathrm{d} t=B \sigma^{n} \text {. }
$$

In Equation (2), $\sigma$ is a uniaxial tensile or compressive stress. (The exponent $n$ is approximately equal to $n \approx 3$. In Equation (1) and in the equations below, the exponent $n$ is set equal to $n=3$. The constant $B$ is equal to $B=3 \times 10^{-17} \mathrm{~Pa}^{-3}$ year $^{-1}=9.6 \times 10^{-25} \mathrm{~Pa}^{-3} \mathrm{~s}^{-1}$ (Paterson, 1981; Weertman, 1983).)

The length $\lambda_{c a}$ of the water-filled cavity behind the obstacle of Figures 2 and 3 is of the order of

$$
\lambda_{\mathrm{ca}} \approx c_{\mathrm{ca}} L\left[\left(P_{\mathrm{u}}-P_{\mathrm{i}}\right) /\left(P_{\mathrm{i}}-P_{\mathrm{w}}\right)\right]^{3},
$$

where the dimensionless constant $c_{\mathrm{ca}}$ is approximately equal to $c_{\mathrm{ca}} \simeq 6 c_{\mathrm{v}}$ and $P_{\mathrm{w}}=P_{\mathrm{d}}$ is the pressure of the water within the cavity. When $P_{\mathrm{w}}=P_{\mathrm{i}}-P_{\mathrm{u}}$, by symmetry of the stress field about an obstacle, there must be complete closure of ice on the down-stream side of an obstacle. Hence the constant $c_{\text {ca }}$ is of the order of but less than 1 to insure that $\lambda_{\mathrm{ca}}<L$ when $P_{\mathrm{w}} \approx P_{\mathrm{i}}-P_{\mathrm{u}}$. (This is the case if the effective stress $\sigma$ that causes creep around the upstream side of the obstacle is $\sigma \approx(1 / 2)\left(P_{\mathrm{u}}-P_{\mathrm{i}}\right)$ or $(1 / 3)$ $\left(P_{\mathrm{u}}-P_{\mathrm{i}}\right)$.

Equation (3) is obtained by noting that the closure velocity $\mathrm{d} r_{\mathrm{ca}} / \mathrm{d} t$ of the cavity is given by (Nye, 1953; see also equation (11) in Weertman, 1972)

$$
\mathrm{d} r_{\mathrm{ca}} / \mathrm{d} t=(1 / 6) B r_{\mathrm{ca}}\left(P_{\mathrm{i}}-P_{\mathrm{w}}\right)^{3}
$$

Since ice moves past the obstacle at the velocity given by Equation (1), integration of Equation (4) leads to

$$
r_{\mathrm{ca}}=\operatorname{Lexp}\left\{-(B x / 6 V)\left(P_{\mathrm{i}}-P_{\mathrm{w}}\right)^{3} .\right.
$$

Here $x$ is distance from the obstacle measured in the downstream direction. At a distance of the order of $x=\lambda_{\mathrm{ca}}$, where $\lambda_{c a}$ is given by Equation (3), the cavity is almost closed.

Because water is continuously produced at the bed, it must, in any approximate steady-state situation, continuously flow out from beneath the glacier. In this situation, water cannot accumulate in the lee-side cavities. Hence, as shown in Figures 2 and 3 , an exit channel must exist at the rear of the cavity. (Although exit channels are R-channels, they are called exit channels rather than $\mathbf{R}$-channels in this paper to emphasize that they are a continuation of a cavity.)

Let $W_{\text {cc }}$ be the water flux passing through a linked cavity-channel water-flow path. The radius $r_{\text {ch }}$ of the exit channel required to transport the water flux out of a cavity is

$$
r_{\mathrm{ch}}=\left\{8 n W_{\mathrm{cc}} / \pi P^{\prime}{ }_{\mathrm{ch}}\right\}^{1 / 4}
$$

where $P^{\prime}$ ch is the pressure gradient within the exit channel and $n$ is the viscosity of water $(\eta=0.0018 \mathrm{~Pa} \mathrm{~s})$. The water flow is assumed to be laminar. (Equation (6) is the usual equation of flow of a fluid through a pipe.) The water pressure within the exit channel is virtually the same as within the cavity because the drop in water pressure from one water cavity to the next cavity down-stream from it is equal to $P^{\prime}{ }_{\text {av }} L$, where $P^{\prime}{ }^{a y}=-\mathrm{d} P_{\mathrm{i}} / \mathrm{d} x$ and $x$ is distance down the glacier. Here $P^{\rho^{\mathrm{av}}}$ is the average value of the water-pressure gradient down the glacier. Since $P^{\prime}$ av $\cong \rho g \alpha$, where $\alpha$ is the surface slope and $P_{w}$ is of the order of magnitude of $P_{i}=\rho g h$, the pressure drop between two cavities is very small compared with the water pressure itself.

The water pressure $P_{\mathrm{w}}$ within the exit channel must satisfy the equation

$$
P_{\mathrm{i}}-P_{\mathrm{w}} \simeq\left\{3 r_{\mathrm{ch}}{ }^{2} P^{\prime}{ }_{\mathrm{ch}}^{2} E / 8 \pi B\right\}^{1 / 3} .
$$

The constant $E$ is the one that converts mechanical work to the amount of ice melted $\left(E=3.2 \times 10^{-9} \mathrm{~m}^{3} \mathrm{~J}^{-1} \equiv 3.2 \times\right.$ $10^{-9} \mathrm{~Pa}^{-1}$ ). (Equation (7) is the same as equation (17) of Weertman (1972). Note that there are typographical errors in equation (17) which can be found and then corrected by combining equations (3) and (12) of Weertman (1972).) Equation (7), which was originally derived by Röthlisberger (1972), is found by insuring that creep closure of water channels is exactly balanced by tunnel enlargement from melting of ice of the channel walls by the heat dissipated in flowing water.

If Equations (6) nd (7) are combined:

$$
P_{\mathrm{i}}-P_{\mathrm{w}}=\left\{9 P^{\prime}{ }_{\mathrm{ch}}^{3} E^{2} W_{\mathrm{cc}} / 8 \pi n B^{2}\right\}^{1 / 6} \text {. }
$$

At a distance of about $L$ up-stream from an obstacle the exit channel enters a region of high-pressure ice. The channel radius in this region constricts from the value of $r_{\text {ch }}$ to the value $r_{h p}$ at a velocity

$$
\mathrm{d} r / \mathrm{d} t=(1 / 6) B r\left(P_{\mathrm{u}}-P_{\mathrm{w}}\right)^{3} .
$$

Integration of this equation gives

$$
r=r_{\mathrm{ch}} \exp \left\{-(B x / 6 V)\left(P_{\mathrm{u}}-P_{\mathrm{w}}\right)^{3}\right\}
$$

where $x$ is measured from the start of the high-pressure ice region. The length $\lambda_{\mathrm{tr}}$ of the transition region in which the channel radius changes from the value of $r_{\mathrm{ch}}$ to the value of $\lambda_{h p}$ is, from Equation (10), equal to

$$
\lambda_{\mathrm{tr}} \simeq c_{\mathrm{ca}} L\left[\left(P_{\mathrm{u}}-P_{\mathrm{i}}\right) /\left(P_{\mathrm{u}}-P_{\mathrm{w}}\right)\right]^{3} .
$$

Since $c_{\mathrm{ca}}$ is of the order of 0.6 to 6 and $P_{\mathrm{w}}<P_{\mathrm{i}}$, the transition length $\lambda_{\text {tr }}$ is smaller than $L$. Hence, except under conditions when $P_{\mathrm{w}}=P_{\mathrm{i}}$, the length of channel $\lambda_{\mathrm{hp}}$ in which the channel radius is constricted to a radius appreciably smaller than $r_{\mathrm{ch}}$ is of the order of $\lambda_{h p} \simeq L$.

The radius $r_{h p}$ of the channel within the high icepressure region is equal to

$$
r_{\mathrm{hp}}=\left\{8 \pi W_{\mathrm{cc}} / \pi P_{\mathrm{hp}}^{\prime}\right\}^{1 / 4}
$$
where $P^{\prime}$ hp is the pressure gradient in the constricted
channel.

The water pressure $P_{\mathrm{W}}$ within the constricted channel must satisfy the equation

$$
P_{\mathrm{u}}-P_{\mathrm{w}} \approx\left\{3 r_{\mathrm{hp}}{ }^{2} P^{\prime}{ }_{\mathrm{hp}}{ }^{2} E / 8 n B\right\}^{1 / 3}
$$


Combining Equations (12) and (13) gives

$$
P_{\mathrm{u}}-P_{\mathrm{W}} \simeq\left\{9 P_{\mathrm{hp}}^{\prime}{ }^{3} E^{2} W_{\mathrm{cc}} / 8 \pi n B^{2}\right\}^{1 / 6} \text {. }
$$

The pressure gradients $P^{\prime}{ }_{\mathrm{ch}}, P^{\prime}{ }_{\mathrm{hp}}$, and $P^{\prime}{ }_{\mathrm{ca}}$, where $P_{\mathrm{ca}}$ is the gradient within the cavity, obviously must obey the equation

$$
\rho g \propto \simeq P^{\prime}{ }_{\mathrm{av}}=\left\{P^{\prime}{ }_{\mathrm{ca}} \lambda_{\mathrm{ca}}+P^{\prime}{ }_{\mathrm{ch}} \lambda_{\mathrm{ch}}+P^{\prime}{ }_{\mathrm{hp}} \lambda_{\mathrm{hp}}\right\} / s L .
$$

This equation, since the pressure gradient in the cavity $P_{\text {ca }}^{\prime} \cong 0$ (because $r_{\text {ca }} \gg r_{\text {ch }}$ ) and $\lambda_{\text {hp }} \cong L$, reduces to

$$
P_{\text {av }}^{\prime}=(1 / s)\left\{\left[(s-1)-\left(\lambda_{\mathrm{ca}} / L\right)\right] P^{\prime}{ }_{\mathrm{ch}}+P^{\prime}{ }_{\mathrm{hp}}\right\} \text {. }
$$

On insertion of Equations (3), (8), and (14) into Equation (15b) gives well as the water pressure $P_{\mathrm{w}}$. It should be noted in Equation (18) that the steady-state cavity length actually decreases when the water supply $W_{c c}$ is increased. The steady-state water pressure $P_{\mathrm{w}}$ decreases as the cavity length decreases and thus decreases when the water supply is increased.

The physical reason for this steady-state behavior is simple. The longer is the cavity the greater is the pressure gradient in the exit channel. The greater is the pressure gradient, for the same water flow, the smaller must be the radius of the exit channel. But the smaller is the radius the greater must be the pressure difference $\left(P_{\mathrm{i}}-P_{\mathrm{W}}\right)$ in order to increase the inward-wall velocity of the channel that contracts the outward-wall velocity produced by melting. The radius of the exit channel is greatest when the cavity length is smallest. The water transport through the exit channel increases when either or both the channel radius $r_{c h}$

$$
P_{\text {av }}^{\prime}=(1 / s)\left(P_{\mathrm{i}}-P_{\mathrm{w}}\right)^{2}\left\{8 \pi n B^{2} / 9 E^{2} W_{\mathrm{cc}}\right\}^{1 / 3}\left\{s-1-c_{\mathrm{ca}}\left[\left(P_{\mathrm{u}}-P_{\mathrm{i}}\right) /\left(P_{\mathrm{i}}-P_{\mathrm{w}}\right)\right]^{3}+\left[\left(P_{\mathrm{u}}-P_{\mathrm{w}}\right) /\left(P_{\mathrm{i}}-P_{\mathrm{w}}\right)\right]^{2}\right\}
$$

Re-arranging Equation (16a):

$$
\begin{aligned}
{\left[\left(P_{\mathrm{i}}-P_{\mathrm{w}}\right) /\left(P_{\mathrm{u}}-P_{\mathrm{i}}\right)\right]^{3} } & =\mathcal{B}\left[\left(P_{\mathrm{i}}-P_{\mathrm{w}}\right) /\left(P_{\mathrm{u}}-P_{\mathrm{i}}\right)^{3}\right]+ \\
& +[1 / s]\left[c_{\mathrm{ca}}-2\left[\left(P_{\mathrm{i}}-P_{\mathrm{w}}\right) /\left(P_{\mathrm{u}}-P_{\mathrm{i}}\right)\right]^{2}-\left[\left(P_{\mathrm{i}}-P_{\mathrm{w}}\right) /\left(P_{\mathrm{u}}-P_{\mathrm{i}}\right)\right]\right\}
\end{aligned}
$$

where

$$
B=\left\{9 E^{2} W_{\mathrm{cc}} P^{\prime}{ }_{\text {av }}^{3} / 8 \pi n B^{2}\right\}^{1 / 3} .
$$

Equation (16b) gives the water pressure $P_{\mathrm{w}}$ when the sliding velocity $V$, the average pressure gradient $P^{\prime}{ }_{\text {av }}$, and the water flux $W_{\text {ce }}$ are specified. (Note that if $V$ is specified then, through Equation (1), $\left(P_{\mathrm{u}}-P_{\mathrm{i}}\right)$ is specified.)

Let $\lambda_{\mathrm{ca}}=\gamma L$. From Equation (3), when $\gamma \gg 1$ with $c_{\mathrm{ca}} \approx 1$,

$$
\left(P_{\mathrm{i}}-P_{\mathrm{w}}\right) /\left(P_{\mathrm{u}}-P_{\mathrm{i}}\right) \propto(1 / \gamma)^{1 / 3} .
$$

Combining Equations (16b) and (17) gives, when $s \gg 1$, is increased or the pressure gradient $P_{\text {h }}$ is increased. Since, in the equations above, a decrease in $P_{\text {ch }}$ requires an increase in $r_{\mathrm{ch}}$, or vice versa, an increase in water transport actually comes about because the increase in radius $r_{\text {ch }}$ is more effective in increasing the water flow than the decrease in pressure gradient $P^{\prime}$ ch is in decreasing the flow.

The largest water flux that can transport in a steadystate situation of Figures 1,2 , and 3 is given by Equation (18b) with $\gamma$ set equal to approximately 1 to 3 . Thus

$$
\left(W_{\mathrm{cc}}\right)_{\max }=\left\{8 \pi n B^{2} / 9 E^{2} P^{\prime}{ }_{\text {av }}^{3}\right\}\left(P_{\mathrm{u}}-P_{\mathrm{i}}\right)^{6} .
$$

At this maximum water flux the value of the water pressure has its smallest value.

$$
\left(P_{\mathrm{u}}-P_{\mathrm{i}}\right)=\gamma^{1 / 3}\left(P_{\mathrm{i}}-P_{\mathrm{w}}\right)=\left[s^{1 / 2} \gamma^{1 / 3} /\left\{s-\gamma c_{\mathrm{ca}}+2 \gamma^{1 / 3}+\gamma^{2 / 3}\right\}^{1 / 2}\right]\left(9 E^{2} W_{\mathrm{cc}} P^{\prime}{ }_{\mathrm{av}}{ }^{3} / 8 \pi n B^{2}\right\}^{1 / 6}
$$

When $\gamma$ is small compared with $s$, Equation (18) reduces to

$\left(P_{\mathrm{u}}-P_{\mathrm{i}}\right) \approx \gamma^{1 / 3}\left(P_{\mathrm{i}}-P_{\mathrm{w}}\right) \approx \gamma^{1 / 3}\left\{9 E^{2} W_{\mathrm{cc}} P_{\mathrm{av}}^{\prime}{ }^{3} / 8 \pi n B^{2}\right\}^{1 / 6}$

The pressure difference $\left(P_{\mathrm{i}}-P_{\mathrm{W}}\right)$ is equal to $\left(P_{\mathrm{i}}-\right.$ $\left.P_{\mathrm{w}}\right) \approx\left(P_{\mathrm{u}}-P_{\mathrm{i}}\right)$ when $\gamma \approx 1$. This is the condition that no cavity forms behind an obstacle because the ice closes in behind an obstacle as fast as it spreads apart ahead of the obstacle. (Note that the ice pressure $P_{\mathrm{d}}$ behind an obstacle is equal to $P_{w}$.)

When $\gamma$ is almost equal to $s$, Equation (18) reduces to (with $c_{\mathrm{ca}} \approx 1$ )

$\left(P_{\mathrm{u}}-P_{\mathrm{i}}\right) \simeq s^{1 / 3}\left(P_{\mathrm{i}}-P_{\mathrm{w}}\right) \approx s^{1 / 2}\left\{9 E^{2} W_{\mathrm{cc}} P_{\mathrm{av}}^{\prime}{ }^{3} / 8 \pi n B^{2}\right\}^{1 / 6}$.

Once the sliding velocity is fixed, the pressure $P_{\mathrm{u}}$ is also fixed. With $P_{\mathrm{u}}$ known, Equation (18) then determines, in a steady-state situation, the cavity length $\lambda_{c a}=\gamma L$ as
The smallest water flux that can transport in a steadystate situation is given by Equation (18c). Thus

$$
\left(W_{\mathrm{cc}}\right)_{\min }=(1 / s)^{3}\left\{8 \pi n B^{2} / 9 E^{2} P^{\prime}{ }_{\text {av }}^{3}\right\}\left(P_{\mathrm{u}}-P_{\mathrm{i}}\right)^{6} .
$$

The water pressure $P_{\mathrm{w}}$ has its greatest value when the water flux is given by Equation (19b).

What happens if the water flux $W_{c c}$ is smaller than the value given by Equation (19b)? Obviously, no steady state involving water flow only through a cavity channel system is possible. (This is also true if the water flux is larger than that given by Equation (19a). However, from the calculations given below, it is very unlikely that the water flux is ever so great that $W_{c c}>\left(W_{c c}\right)_{\max }$.) But a steadystate solution is possible in which the water leaks out of the cavities. Consider Figure 4. Cavities extend from the rear of one obstacle to the front of the next down-stream obstacle. The high-pressure ice region closes off a cavity. The excess water must leak out of the cavity into a water film (see Fig. 4). When water leaks out of the cavities, the water pressure in a cavity is equal to the ice-overburden pressure. (Note that in Equation (18c) $P_{\mathrm{w}} \simeq P_{\mathrm{i}}$ when $s \gg 1$. In the next section it is shown that the term $s$ actually should be replaced with a term $S$ where $S \gg s>1$.) 


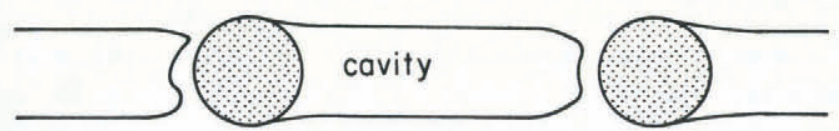

Fig. 4. Same figure as Figure 2 when cavities extend to the next obstacle and the water flux is too great to be carried by a cavity-channel system.

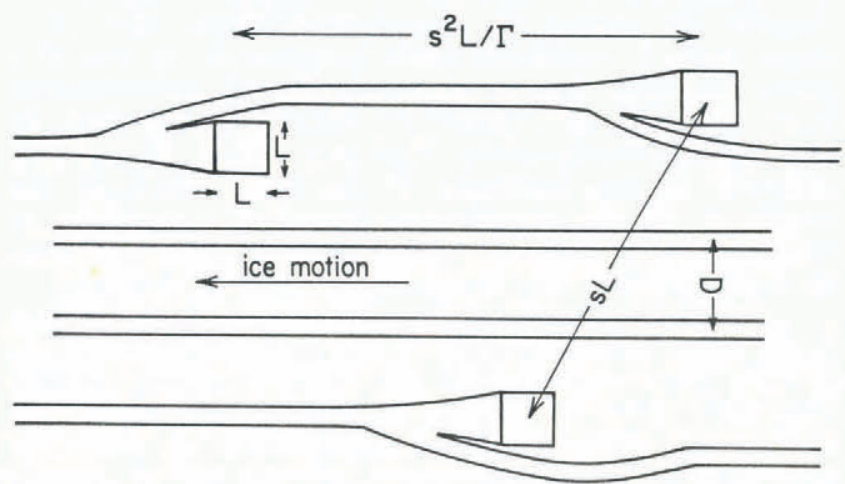

Fig. 5. Looking down on a glacier bed with randomly spaced obstacles. Large obstacles are not shown. Each obstacle has a lee-side water cavity with an exit channel that connects with a down-stream water cavity.

The conclusion to be reached from the equations of this section is that, if the water flux is smaller than a critical one, the water pressure rises to a value equal to the ice-overburden pressure and water leaks from the cavities into a water film between the cavities.

\section{Obstacles in a random array}

A somewhat more realistic bed than one consisting of an array of obstacles in a simple cubic pattern is one in which the obstacles are placed in a random array (see Fig. 5 ). Let the average spacing between obstacles of size $L$ again be equal to $s L$. On simple probability grounds, the length an exit channel must have for it to join a downstream cavity is now $S L$, where $S=s^{2} / \mathrm{I}$. The constant I takes into account how close a channel must approach a down-stream obstacle to be "captured" by that obstacle's cavity. A reasonable estimate for $\mathrm{I}$ is $\mathrm{I} \approx 2-3$. The channel formed behind one obstacle that is "captured" by a down-stream obstacle, as in the previous section, passes through a region of ice which is subjected to much higher than the nominal ice pressure $P_{\mathrm{j}}$. It must pass through a region in which the ice pressure is of the order of $P_{u}$. The separation distance $D$ between exit channels is $D \approx r L$. (For the bed of the previous section $D=s L$.)

Let the analysis of the previous section be repeated for the random obstacle bed. When it is, it is found that the only formal change needed in the equations is to replace the term $s$ with the term $S$. (Of course, since there are now more water paths, since the separation distance between paths is decreased from $D=s L$ to $D=\Gamma L$, the water flux $W_{\text {cc }}$ in each path is decreased by the amount $\mathrm{T} / \mathrm{s}$ if the total water flow down the glacier bed is unchanged.) Equation (19a) remains unchanged. Equation (19b) becomes

$$
\begin{aligned}
\left(W_{\mathrm{cc}}\right)_{\min } & \approx(1 / S)^{3}\left\{8 \pi \eta B^{2} / 9 E^{2} P^{\prime}{ }_{\text {av }}^{3}\right\}\left(P_{\mathrm{u}}-P_{\mathrm{i}}\right)^{6} \\
& =\left(\mathrm{I} / s^{2}\right)^{3}\left\{8 \pi \eta B^{2} / 9 E^{2} P^{\prime}{ }_{\text {av }}^{3}\right\}\left(P_{\mathrm{u}}-P_{\mathrm{i}}\right)^{6} .
\end{aligned}
$$

\section{Sliding velocity, shear stress, and friction stress}

Equation (1) relates the up-stream ice pressure $P_{\mathrm{u}}$ with the sliding velocity $V$. The sliding is a result of a shear stress $\tau(\tau \cong \rho g \alpha)$ that acts across the bed. By the usual balance-of-force argument, the shear stress satisfies the equation if the rock-ice interface is frictionless and the bed is that of Figures 1 through 5 with only one size of obstacles. (If very large obstacles are present, as shown in Figure 1, Equation (20) remains valid because large obstacles offer so little resistance to the sliding motion.) The value of $P_{u}$ estimated from Equation (20) is too large because in a real bed obstacles that are both smaller than and larger than the controlling obstacles help support the shear stress across the bed.

The effect of obstacles smaller and somewhat larger than the controlling obstacle size can be mimicked in a single-obstacle-size bed model by allowing the ice-rock interface to support a finite shear stress $\tau_{\mathrm{f}}$, where $\tau_{f}=\xi^{\prime} \tau$, where the term $\xi^{\prime}$ lies in the range $0<\xi^{\prime}<1$. The influence of a water film of thickness $w$ can also be mimicked by considering that the "friction stress" is given by the equation

$$
\tau_{\mathrm{f}}=\xi \tau
$$

where $\xi=\xi^{\prime}(1-(w / 2 L)$ if $w<2 L$ and $\xi=0$ if $\xi>2 L$. (In this approximation, if the water film has drowned the controlling obstacles and the obstacles are twice the controlling obstacle size, the "friction" stress is reduced to a value $\tau_{\mathrm{f}}=0$.)

Equation (20) is altered when the friction stress is given by Equation (21). Equation (20) is changed to

$$
\left(\tau-\tau_{\mathrm{f}}\right) \approx\left(P_{\mathrm{u}}-P_{\mathrm{w}}\right) / \mathrm{s}^{2} .
$$

The sliding velocity $V$ is found from Equations (1) and (22) and is equal to

$$
V=c_{\mathrm{v}} B L\left(P_{\mathrm{u}}-P_{\mathrm{i}}\right)^{3}=c_{\mathrm{v}} B L\left\{\tau^{\prime}-\left(P_{\mathrm{i}}-P_{\mathrm{w}}\right)\right\}^{3}
$$

where $\tau^{\prime}=s^{2}\left(\tau-\tau_{f}\right)$

The amount of water $W_{\mathrm{f}}$ produced per unit time between two of the exit channels (see Fig. 5) is equal to

$$
\begin{aligned}
W_{\mathrm{cc}} & \approx E \Lambda \Gamma L\left[\tau V+M_{\mathrm{gt}}\right]=E \Lambda \Gamma L\left[\tau c _ { \mathrm { v } } B L \left\{\tau^{\prime}-\right.\right. \\
& \left.\left.-\left(P_{\mathrm{i}}-P_{\mathrm{w}}\right)\right\}^{3}+M_{\mathrm{gt}}\right] .
\end{aligned}
$$

In Equation (24) $M_{\text {g }}$ is the geothermal heat (expressed in mechanical units) and $\Lambda$ is the distance to the head of the glacier. (The approximation is made in Equation (24) that the sliding velocity $V$ does not vary down the glacier.)

The critical water flux $\left(W_{\mathrm{cc}}\right)_{\text {in }}$ given by Equation (19b) required that $P_{\mathrm{i}}=P_{\mathrm{w}}$. Thus, from Equation (23),

$$
\tau^{\prime}=\left(P_{\mathrm{u}}-P_{\mathrm{i}}\right)
$$

and the sliding velocity is equal to

$$
V=c_{\mathrm{v}} B L \tau^{\prime 3} \text {. }
$$

The following equation is obtained for the critical distance $\Lambda$ from the head of a glacier at which a water film can no longer form at a glacier bed (when $W_{\text {cc }}$ given by Equation $(24)$ is set equal to the critical value. $\left(W_{c c}\right)_{\min }$ given by Equation (19c) and Equations (25) and (26) are substituted into the resultant equation).

$$
\Lambda=\left\{8 \pi n B^{2} / 9 E^{3} P^{\prime}{ }_{\mathrm{av}}^{3}\right\} \tau^{\prime 6} / S^{3}\left\{\Gamma L\left[\tau c_{\mathrm{v}} B L \tau^{\prime 3}+M_{\mathrm{gt}}\right]\right\} .
$$

In the approximation that $M_{\mathrm{gt}} \approx 0$, this equation reduces to

$$
\Lambda=\left\{8 \pi \eta B / 9 E^{3} P^{\prime}{ }_{\text {av }}{ }^{3} \Gamma c_{\mathrm{v}} L^{2}\right\}\left(\tau^{\prime 3} / \tau\right)(1 / S)^{3} .
$$

Since $\tau_{\mathrm{f}} \cong \xi \tau$, where $0<\xi<1$, Equation (27b) is reduced further to

$$
\begin{aligned}
\Lambda & =8 \pi \eta(1-\xi)^{3} s^{6} B \tau^{2} / 9 S^{3} E^{3} P^{\prime}{ }_{\mathrm{av}}{ }^{3} \Gamma c_{\mathrm{v}} L^{2} \\
& =8 \pi \eta(1-\xi)^{3} B \tau^{2} \mathrm{I}^{2} / 9 E^{3} P^{\prime}{ }_{\mathrm{av}}{ }^{3} c_{\mathrm{v}} L^{2} .
\end{aligned}
$$


The critical water flux $\left(W_{\mathrm{cc}}\right)_{\max }$ given by Equation (19a) requires that $\left(P_{\mathrm{u}}-P_{\mathrm{i}}\right)=\left(P_{\mathrm{i}}-P_{\mathrm{w}}\right)$. When $\left(P_{\mathrm{u}}-P_{\mathrm{i}}\right)$ $=\left(P_{\mathrm{i}}-P_{\mathrm{w}}\right)$, according to Equation (23),

$$
\tau^{\prime}=2\left(P_{\mathrm{u}}-P_{\mathrm{i}}\right)=2\left(P_{\mathrm{i}}-P_{\mathrm{w}}\right)
$$

and the sliding velocity is equal to

$$
V=(1 / 8) c_{\mathrm{v}} B L \tau^{\prime 3} .
$$

The following equation, which is analogous to Equation (27c), is obtained for the critical distance $\Lambda$

$$
\Lambda=\pi \eta(1-\xi)^{3} s^{6} B \tau^{2} / 9 E^{3} P^{\prime}{ }_{\mathrm{av}}{ }^{3} \Gamma c_{\mathrm{v}} L^{2} .
$$

The value of $s$ required for a given sliding velocity can be found after noting that $\tau^{\prime}=(1-\xi) s^{2} \tau$. Thus

$$
s=\left(V / c_{\mathrm{v}} B L\right)^{1 / 6} /[(1-\xi) \tau]^{1 / 2}
$$

when $V$ is given by Equation (26) and

$$
s=\left(V / c_{\mathrm{v}} B L\right)^{1 / 6}[2 /(1-\xi) \tau]^{1 / 2}
$$

when $V$ is given by Equation (29).

The values of the critical distance $\wedge$ given by Equations (27c) and (30) are listed in Table I for different

\begin{tabular}{|c|c|c|c|c|c|}
\hline \multicolumn{3}{|c|}{ For $\left.(W)_{\mathrm{cc}}\right)_{\min }$} & \multicolumn{3}{|c|}{ For $\left(W_{\mathrm{cc}}\right)_{\max }{ }^{\dagger}$} \\
\hline$\xi$ & $s$ & $\stackrel{\wedge}{\mathrm{km}}$ & $s$ & & $\begin{array}{c}\wedge \\
\mathrm{km}\end{array}$ \\
\hline 0.95 & 44.7 & 2.69 & 63.2 & 7.93 & $\times 10^{8}$ \\
\hline 0.9 & 31.6 & 21.5 & 44.7 & 7.93 & $\times 10^{8}$ \\
\hline 0.8 & 22.3 & 172 & 31.6 & 7.93 & $\times 10^{8}$ \\
\hline 0.7 & 18.2 & 581 & 25.8 & 7.93 & $\times 10^{8}$ \\
\hline 0.6 & 15.8 & 1380 & 22.3 & 7.93 & $\times 10^{8}$ \\
\hline
\end{tabular}
values of $\xi$ and $s$ required to have $V=50 \mathrm{~m} \mathrm{year}^{-1}=$ $1.6 \times 10^{-6} \mathrm{~m} \mathrm{~s}^{-1}$

\section{TABLE I. CRITICAL DISTANCE $\wedge$}

Sliding velocity $V=50 \mathrm{~m}_{\text {year }}^{-1}=1.6 \times 10^{-6} \mathrm{~m} \mathrm{~s}^{-1}$

* From Equation (27c).

From Equation (30).

The constants used in the calculations: $\eta=0.0018 \mathrm{~Pa} \mathrm{~s} ; \tau=$ $100 \mathrm{kPa} ; \quad E=3.2 \times 10^{-9} \mathrm{~m}^{3} \mathrm{~J}^{-1} \equiv 3.2 \times 10^{-9} \mathrm{~Pa}^{-1} ; \quad \mathrm{r}=3$; $L=10 \mathrm{~mm} ; \quad c_{\mathrm{ca}}=1 ; \quad c_{\mathrm{v}}=c_{\mathrm{ca}} / 6 ; \quad S=s^{2} \mathrm{r} ; \quad P_{\text {av }}^{\prime}=$ $333 \mathrm{~Pa} \mathrm{~m}-1$; and $B \stackrel{c a}{=} 9.6 \times 10^{-25} \mathrm{~Pa}^{-3} \mathrm{~s}^{-1}$.

In Table II are given values of $\Lambda$ from Equation (27c) for two fixed values of $s$ and different values of $\xi$. The different sliding velocities for these values of $s$ and $\xi$ are also listed in this table.

TABLE II. CRITICAL DISTANCE $\wedge$

$$
\text { For }\left(W_{\mathrm{cc}}\right)_{\min }{ }^{*}
$$

For $s=44.7$

For $s=31.6$

$\begin{array}{ccc}\boldsymbol{\xi} & \begin{array}{c}\boldsymbol{V} \\ \mathrm{km} / \text { year }\end{array} & \begin{array}{c}\wedge \\ \mathrm{km}\end{array} \\ 0.95 & 0.05 & 2.69 \\ 0.9 & 0.4 & 21.5 \\ 0.8 & 3.2 & 172 \\ 0.7 & 10.8 & 581 \\ 0.6 & 25.6 & 1380\end{array}$

$\begin{array}{lr}\begin{array}{c}V \\ \mathrm{~km} / \text { year }\end{array} & \begin{array}{r}\wedge \\ \mathrm{km}\end{array} \\ 0.00625 & 2.7 \\ 0.05 & 21.5 \\ 0.4 & 172 \\ 1.35 & 581 \\ 3.2 & 1380\end{array}$

* From Equation (27c).

See Table I for values of the constants.
The values of the term $\xi$ listed in Tables I and II $(0.95 \leqslant \xi \leqslant 0.6)$ require that obstacles other than the controlling obstacles support $40-95 \%$ of the basal shear stress. For a bed with a full spectrum of obstacle sizes, we estimated (Weertman, 1964) the controlling obstacles supported only about $30-50 \%$ of the basal shear stress.

The following result in Tables $I$ and $I I$ should be noted: (a) The value of $\Lambda$, for the critical water flux $\left(\mathrm{W}_{\mathrm{cc}}\right)_{\min }$ predicted by Equation $(27 \mathrm{c})$ is extremely large for a glacier bed in which controlling size obstacles support an appreciable fraction of the basal shear stress. Consequently, it is unrealistic to expect that this critical length is ever exceeded for glaciers of unexceptional length. Thus, in a glacier there is insufficient water generated at the base of a glacier to keep open a continuous linked cavity-channel system. (If the high-pressure ice regions did not exist, an open linked channel-cavity flow-path system would exist regardless of the magnitude of the water flux.) (b) The distance $\Lambda$, for the critical water flux $\left(W_{\mathrm{cc}}\right)_{\max }$ predicted by Equation (30) is orders of magnitude larger than that given by Equation (27c). This length should never be exceeded.

The implications of these results are: the water pressure $P_{\mathrm{w}}$ in water cavities is equal to the ice-overburden pressure $P_{\mathrm{i}}$. The water cavities have the maximum length possible. They start behind one obstacle and end in front of the next down-stream cavity. The water cavities close up within the high-pressure ice regions. Water generated at an obstacle must flow out of a water cavity into the water film that exists in the regions between cavities. (A water film itself is unstable (Walder, 1982). Periodically, the film should collapse into $\mathbf{R}$-channels. These $\mathbf{R}$-channels themselves are unstable and they should collapse and the water film re-form (Weertman and Birchfield, 1983[b]). The cycle of water film into $\mathrm{R}$-channel into water film should repeat itself.)

These predicted results require that water transported through Nye channels is a minor fraction to the total water flow. The analysis that led to these predictions contained the assumption that surface melt water which descends to the glacier bed does not dominate the basal water hydraulics. If surface water increases the water flux by several orders of magnitude in the equations above, the value of $\Lambda$ is reduced several orders of magnitude. Opencavity channel-flow paths are then quite likely to exist. A more abundant water flow would lead in this situation to a decrease in the water pressure.

\section{Large obstacles}

Large obstacles have been ignored so far. Suppose a set of large obstacles of size $L^{*} \gg L$ exist in addition to the controlling obstacles (see Fig. 1). What are the conditions for cavity formation behind them and a linked cavity channel system? with

For a given sliding velocity, Equation (1) is replaced

$$
V=c_{\mathrm{v}} B L^{*}\left(P_{\mathrm{u}}^{*}-P_{\mathrm{i}}\right)^{3}
$$

where $P_{\mathrm{u}}{ }^{*}$ is the up-stream ice pressure at the obstacle. Equation (3) becomes

$$
\lambda_{\mathrm{ca}}^{*}=c_{\mathrm{ca}} L^{*}\left[\left(P_{\mathrm{u}}^{*}-P_{\mathrm{i}}\right) /\left(P_{\mathrm{i}}-P_{\mathrm{w}}{ }^{*}\right)\right]^{3}
$$

where $\lambda_{c a}{ }^{*}$ is the length of the cavity behind the large cavity and $P_{\mathrm{w}}{ }^{*}$ is the water pressure within the cavity.

Other equations derived for the obstacles of size $L$ are changed in similar ways. Equation (27c) for the minimum water flux is altered to

$$
\Lambda^{*}=8 \pi n\left(1-\xi^{*}\right)^{3} B T^{2} \mathrm{r}^{2} / 9 E^{3} P^{\prime}{ }_{\text {av }}{ }^{3} c_{\mathrm{v}} L^{* 2} .
$$

Equation (30) for the maximum water flux is changed to

$$
\Lambda^{*}=\pi \eta\left(1-\xi^{*}\right)^{3} s^{6} B \tau^{2} / 9 E^{3} P^{\prime}{ }_{\text {av }}^{3} \Gamma c_{\mathrm{v}} L^{* 2} .
$$

The value of $\xi^{*}$ in Equations (34) and (35) is equal to 0 if $w \geqslant 2 L$. It is equal to 


$$
\xi^{*}=1-(1-\xi)\left(L / L^{*}\right)^{1 / 3}
$$

if $w \ll L$ and long cavities are behind both small and large cavities and

$$
\xi^{*}=1-2(1-\xi)\left(L / L^{*}\right)^{1 / 3}
$$

and long cavities exist only behind the small obstacles. The value of $\xi^{*}$ given by Equation (36a) is estimated by noting that the effective stress $s^{2}(1-\xi) \tau$, causing flow past obstacles of size $L$ is, from Equation (1), proportional to $(V / L)^{1 / 3}$. For the large obstacles, the effective stress $s^{2}\left(1-\xi^{*}\right)$ is proportional to $\left(V / L^{*}\right)^{1 / 3}$ according to Equation (34). Since the sliding velocity is the same for the large and small obstacles, $\xi^{*}$ has the value given above. The value of $\xi^{*}$ given by Equation (36b) is found in a similar way. If no cavity forms behind a large obstacle, the effective stress, which is proportional to $\left(V / L^{*}\right)^{1 / 3}$, is $(1 / 2) s^{2}\left(1-\xi^{*}\right) \tau$.

Table III, which is the analogue of Table I, gives values of $\Lambda^{*}$ predicted (with the constants used in Table I) by Equations (34), (35), and (36b) when $L^{*}=1 \mathrm{~m}$ and $w \ll L=10 \mathrm{~mm}$. Note that $\xi^{*} \approx 1$. It can be seen from Table III that the critical lengths $\Lambda^{*}$ are orders of magnitude smaller than those given in Table $I$.

\section{TABLE III. CRITICAL DISTANCE $\Lambda^{*}$}

\begin{tabular}{|c|c|c|c|c|c|c|}
\hline \multirow[b]{2}{*}{$\xi$} & \multirow[b]{2}{*}{$\xi^{*}$} & \multicolumn{3}{|c|}{ For $\left(W_{\mathrm{cc}}\right)_{\min }{ }^{*}$} & \multicolumn{2}{|c|}{ For $\left(W_{\mathrm{cc}}\right)_{\max }{ }^{\dagger}$} \\
\hline & & $s$ & $\begin{array}{c}\Lambda^{*} \\
\mathrm{~m}\end{array}$ & $\gamma^{*}$ & $s$ & $\begin{array}{l}\Lambda^{*} \\
\mathrm{~km}\end{array}$ \\
\hline 0.95 & 0.9954 & 44.7 & 0.0215 & 35.6 & 63.2 & 6350 \\
\hline 0.9 & 9.9907 & 31.6 & 0.172 & 35.6 & 44.7 & 6350 \\
\hline 0.8 & 0.9814 & 22.3 & 1.38 & 35.6 & 31.6 & 6350 \\
\hline 0.7 & 0.97215 & 18.2 & 4.65 & 35.6 & 25.8 & 6350 \\
\hline 0.6 & 0.9629 & 15.8 & 11.0 & 35.6 & 22.3 & 6350 \\
\hline
\end{tabular}

Sliding velocity $V=50 \mathrm{~m}_{\text {year }}^{-1}=1.6 \times 10^{-6} \mathrm{~m} \mathrm{~s}^{-1}$

The constants used in the calculations are the same as in Table I except for: $L^{*}=1 \mathrm{~m} ;\left(1-\xi^{*}\right)=2(1-\xi)\left(L / L^{*}\right)^{1 / 3}$. The value of $\gamma^{*}=\lambda_{\text {ca }}{ }^{*} / L^{*}$ is at $\Lambda=5 \mathrm{~km}$.

The length $\lambda_{c a}=\gamma^{*} L^{*}$ of a water cavity behind a large obstacle is found from the equation (which is the analogue of Equation (18a))

TABLE IV. CRITICAL DISTANCE $\Lambda^{*}$

$$
\text { For }\left(W_{c c}\right)_{\min } *
$$

$$
\text { For } s=22.3
$$

$\begin{array}{ccc}\xi^{*} & \begin{array}{c}V \\ \mathrm{~km} / \text { year }\end{array} & \begin{array}{c}\Lambda^{*} \\ \mathrm{~km}\end{array} \\ 0 & 625 & 2.15\end{array}$

$\begin{array}{lll}0 & 625 & 2.15\end{array}$

\section{For $s=22.3$}

$0 \quad 6251.23 \times 10^{6}$

* From Equation (34).

+ From Equation (35).

See Table I for values of other constants except for $L^{*}=1 \mathrm{~m}$. The value of $\gamma^{*}=\lambda_{\mathrm{ca}}^{*} / L^{*}$ is at $\Lambda=5 \mathrm{~km}$.

(The Table IV results apply when the only obstacles holding up the glacier are the large obstacles.)

The values of $\gamma^{*}$ in Tables III and IV are calculated using Equation (39). It is seen in these two tables that increasing the amount of the basal shear stress that is supported by the larger obstacles increases the length of the cavities behind the larger obstacles.

\section{Effect of melt water from the upper surface}

Suppose surface melt water that descends to the glacier bed is able to escape from R-channels and mingle with the water generated at the bed. For mathematical simplicity let the surface melt-water generation rate be constant and equal to $(\zeta-1)$ times the melt generated at the bed. Equations (17c) and (30) become

$$
\begin{aligned}
\Lambda & =8 \pi \eta(1-\xi)^{3} s^{6} B \tau^{2} / 9 S^{3} E^{3} P^{\prime}{ }_{\text {av }}^{3} \Gamma c_{\mathrm{v}} L^{2} \\
& =8 \pi \eta(1-\xi)^{3} B \tau^{2} \mathrm{r}^{2} / 9 \zeta E^{3} P^{\prime}{ }_{\text {av }}^{3} c_{\mathrm{v}} L^{2}
\end{aligned}
$$

and

$$
\Lambda=\pi \eta(1-\xi)^{3} s^{6} B \tau^{2} / 9 \zeta E^{3} P^{\prime}{ }_{\mathrm{av}}^{3} \mathrm{\Gamma} c_{\mathrm{v}} L^{2} .
$$

In Tables I and II the critical distances $\wedge$ are reduced by a factor of $\zeta$. From these tables it is seen that the

$$
\left(P_{\mathrm{u}}{ }^{*}-P_{\mathrm{i}}\right)=\gamma^{* 1 / 3}\left(P_{\mathrm{i}}-P_{\mathrm{w}}{ }^{*}\right)=\left[S^{1 / 2} \gamma^{* 1 / 3} /\left\{S-\gamma^{*} c_{\mathrm{ca}}+2 \gamma^{* 1 / 3}+\gamma^{* 2 / 3}\right\}^{1 / 2}\right]\left\{9 E^{2} W_{\mathrm{cc}} P^{\prime}{ }_{\mathrm{av}}^{3} / 8 \pi n B^{2}\right\}^{1 / 6} .
$$

Using Equations (32) and (37), the ratio $\gamma^{*}=\lambda^{*} / L^{*}$, at a distance $\Lambda$ from the head of a glacier, is given by the equation

$$
\left.\gamma^{*}=\left\{S-\gamma^{*} c_{\mathrm{ca}}+2 \gamma^{* 1 / 3}+\gamma^{* 2 / 3}\right)\right\}^{3 / 2}\left\{(\Lambda)_{\min } / \Lambda\right\}^{1 / 2} .
$$

In Equation (38) the term $(\Lambda)_{\min }$ is the value of $\Lambda$ when the water flux $W_{\mathrm{cc}}=\left(W_{\mathrm{cc}}\right)_{\min }$. When $\gamma^{*} \ll S \equiv s^{2} / \mathrm{r}$, Equation (38) becomes

$$
\gamma^{*} \simeq S^{3 / 2}\left\{(\Lambda)_{\min } / \Lambda\right\}^{1 / 2} .
$$

When $\gamma^{*} \approx S \equiv s^{2} / \mathrm{r}$, Equation (38) becomes

$$
\gamma^{*} \simeq S\left\{(\Lambda)_{\min } / \Lambda\right\}^{1 / 2} .
$$

Table IV presents values of $\Lambda^{*}$ and $V$ for the case of $\xi^{*}=0$ using some of the values of $s$ given in Table III. presence at the bed of abundant surface melt water can reduce the critical distance $\Lambda$ to values sufficiently small that water can flow through a linked cavity channel system. (Before it can be concluded that this can happen, it is still necessary to show that the surface melt water can escape from $\mathrm{R}$-channels and mingle with the water produced at the bed.)

\section{DISCUSSION AND IMPLICATIONS}

The analysis of this paper is based on a very simplified glacier bed. It is strongly emphasized that this particular bed is not proposed here to be a close approximation to actual glacier beds. Rather, the model bed is used as a tool to reveal in as uncomplicated a manner possible essential facts about basal water flow. We believe the bed model is sufficiently realistic that its simplicity does not invalidate the main conclusion reached in this paper. This conclusion is that the high-pressure, up-stream sides of bed 
irregularities play just as important a role in basal water mechanics as do the low-pressure, cavity-forming regions on their down-stream sides.

The calculations in the preceding sections reveal that in a steady-state situation in which all the water is produced at the glacier bed a water film should form and the water pressure should equal the overburden-ice pressure. Long, sealed off cavities form behind the controlling obstacles. A linked cavity channel flow-path system does not form.

The simplified bed model used in this paper does not contain Nye channels that are incised into the bedrock. The existence of an extensive network of $\mathrm{N}$-channels, obviously, prevents the build-up of a thick water film under normal amounts of water. Since the carrying capacity of $\mathrm{N}$-channels is limited, once excessive amounts of water are present these channels cannot prevent the formation of water films of appreciable thickness if other factors are favorable for their formation. Rothlisberger channels that transport surface melt water can also hinder the development of thick water films particularly during periods of decreasing surface-melt supply when these channels must contract their radii. On the other hand, during periods of increasing surface meltwater supply, when the $\mathrm{R}$-channels must expand their radii, these channels can aid the formation of water films because water must flow transversely out of $\mathrm{R}$-channels.

One way the simplified glacier-bed model used in this paper is deficient is that it cannot easily take account of the effect of gradients in the basal shear stress that served as the basis of a theory of surge initiation of Robin and Weertman (1973).

In this paper the power-law exponent $n$ of the creep equation has always been taken to equal $n=3$. The justification for using this value of $n$ for moderate to very large deviatoric stress levels is the recent experimental results of Kirby and others (1985). These investigators found that under a confining hydrostatic pressure the value of $n$ does not increase from the value of 3 at the higher deviatoric stresses. (Older experimental creep data in the literature (Weertman, 1983) on ice obtained at ambient pressure show at higher stress levels a power exponent greater than 3.)

If the power-law exponent $n$ indeed always has a value approximately equal to 3 , it is very difficult to see how pressure increases in themselves can lead to the large changes in glacier sliding velocity that have been attributed to pressure changes. The largest increase in sliding that comes about from a pressure change for a pressure in which no cavity forms behind an obstacle to a pressure equal to the overburden ice pressure is a factor of $2^{n}$ (see Weertman and Birchfield, 1983[a]). Hence the largest increase is only a factor of $2^{3}=8$. This is an upper limit only. A more realistic estimate of the change of sliding velocity produced by a basal water-pressure increase is by a factor $\left(\tau-\tau_{\mathrm{f}}\right) s^{2} /\left[\left(\tau-\tau_{\mathrm{f}}\right) s^{2}-\left(P_{\mathrm{i}}-P_{\mathrm{w}}\right)\right]$, where the water pressure increases from $\left(P_{\mathrm{i}}-P_{\mathrm{u}}\right)$ to $P_{\mathrm{i}}$ where $\left(P_{\mathrm{i}}-P_{\mathrm{w}}\right)=$ $1-2 \mathrm{MPa}$. Since the term $\left(\tau-\tau_{\mathrm{f}}\right) s^{2}$ might be expected to be of the order of $6-8 \mathrm{MPa}$, the increase in sliding produced by the water-pressure change should be of the order of 1.5-3.5 Variegated Glacier increased its velocity by a factor of 100 during its most recent surge (Kamb and others, 1985). It is difficult to understand how a pressure change alone, that reasonably can lead to only at most one order of magnitude increase in sliding velocity, can account for the increased motion of this glacier.

The cavity formation itself will lead to an increased sliding velocity because of the increased separation of the glacier basal ice from the bed. If the fraction of the bed area that is cavitated is $F$, the effective shear stress $\tau$, on the remaining uncavitated bed area is no greater than $\tau /(1-F)$. Since the sliding velocity in any creepcontrolling theory can reasonably be expected to be proportional to $\tau_{\text {eff }} m$, where $m \approx n$, the increased sliding velocity produced by cavitation should be of the order of $[1 /(1-F)]^{n}$ times the initial sliding velocity. A 100 -fold increase in sliding velocity requires a cavitation fraction of $F=0.78$.

If high-pressure zones seal cavities and force water to flow in water films, the high sliding velocities of surges are more easily accounted for. There is no upper limit to the increase in sliding motion that can be produced by water films. The fact that relatively thick water films are unstable (Walder, 1982; Weertman and Birchfield, 1983[b]) and eventually will turn into R-channels is not a fact that can be used against a water-film explanation of fast sliding motion. The R-channels they turn into are themselves unstable and these channels transform back into water films (Weertman and Birchfield, 1983[b]).

\section{ACKNOWLEDGEMENTS}

This research was sponsored in part with funding from the Climate Dynamics Section of the U.S. National Science Foundation under grant ATM-81/1138. An earlier version of this paper was presented at the International Workshop on Hydraulic Effects at the Glacier Bed and Related Phenomena, Interlaken, Switzerland, 18-19 September 1985. I wish to thank G. Robin and an anonymous reviewer for their very helpful and constructive reviews of the earlier version of this paper.

\section{REFERENCES}

Iken, A. 1981. The effect of subglacial water pressure on the sliding velocity of a glacier in an idealized numerical model. Journal of Glaciology, Vol. 27, No. 97, p. 407-21.

Kamb, W.B. 1970. Sliding motion of glaciers: theory and observation. Reviews of Geophysics and Space Physics, Vol. 8, No. 4, p. 673-728.

Kamb, W.B., and others. 1985. Glacier surge mechanism: 1982-1983 surge of Variegated Glacier, Alaska, by W.B. Kamb [and 7 others]. Science, Vol. 227, No. 4686, p. 469-79.

Kirby, S.H., and others. 1985. Rheologies of $\mathrm{H}_{2} \mathrm{O}$ ices $\mathrm{I}_{h}$, II, and III at high pressures: a progress report, by S.H. Kirby, W.B. Durham, and H.C. Heard. (In Klinger, J., and Benest, D., eds. Ices in the solar system. Dordrecht, D. Reidel, p. 89-107. (NATO A.S.I. Series.))

Lliboutry, L. 1968. General theory of subglacial cavitation and sliding of temperate glaciers. Journal of Glaciology, Vol. 7, No. 49, p. 21-58.

Lliboutry, L. 1983. Modifications to the theory of intraglacial waterways for the case of subglacial ones. Journal of Glaciology, Vol. 29, No. 102, p. 216-26.

Nye, J.F. 1953. The flow law of ice from measurements in glacier tunnels, laboratory experiments and the Jungfraufirn borehole experiment. Proceedings of the Royal Society of London, Ser. A, Vol. 219, No. 1139, p. 477-89.

Nye, J.F. 1969. A calculation on the sliding of ice over a wavy surface using a Newtonian viscous approximation. Proceedings of the Royal Society of London, Ser. A, Vol. 311 , No. 1506 , p. 445-67.

Nye, J.F. 1973. Water at the bed of a glacier. Union Géodésique et Géophysique Internationale. Association Internationale d'Hydrologie Scientifique. Commission de Neiges et Glaces. Symposium on the Hydrology of Glaciers, Cambridge, 7-13 September 1969, p. 189-94. (Publication No. 95 de l'Association Internationale d'Hydrologie Scientifique.)

Paterson, W.S.B. 1981. The physics of glaciers. Second edition. Oxford, etc., Pergamon Press. (Pergamon International Library.)

Robin, G. de Q., and Weertman, J. 1973. Cyclic surging of glaciers. Journal of Glaciology, Vol. 12, No. 64, p. 3-18.

Röthlisberger, H. 1972. Water pressure in intra- and subglacial channels. Journal of Glaciology, Vol. 11, No. 62 , p. $177-203$

Shreve, R.L. 1972. Movement of water in glaciers. Journal of Glaciology, Vol. 11, No. 62, p. 205-14.

Walder, J.S. 1982. Stability of sheet flow of water beneath temperate glaciers and implications for glacier surging. Journal of Glaciology, Vol. 28, No. 99, p. 273-93.

Walder, J.S. Unpublished. Spatial and temporal variability in water flow beneath temperate glaciers.

Weertman, J. 1964. The theory of glacier sliding. Journal of Glaciology, Vol. 5, No. 39, p. 287-303. 
Weertman, J. 1972. General theory of water flow at the base of a glacier or ice sheet. Reviews of Geophysics and Space Physics, Vol. 10, No. 1, p. 287-333.

Weertman, J. 1979. The unsolved general glacier sliding problem. Journal of Glaciology, Vol. 23, No. 89, p. 97-115.

Weertman, J. 1983. Creep deformation of ice. Annual Review of Earth and Planetary Sciences, Vol. 11, p. 215-40.
Weertman, J., and Birchfield, G.E. 1983[a]. Basal water film, basal water pressure, and velocity of traveling waves on glaciers. Journal of Glaciology, Vol. 29, No. 101, p. 20-27.

Weertman, J., and Birchfield, G.E. 1983[b]. Stability of sheet water flow under a glacier. Journal of Glaciology, Vol. 29, No. 103 , p. 374-82.

MS. received 11 October 1985 and in revised form 17 June 1986 